RESEARCH ARTICLE

\title{
Designing 'Critical' Heritage Experiences: Immersion, Enchantment and Autonomy
}

\section{Colin Sterling}

This article investigates the critical potential of newly emerging approaches to heritage experience design. Moving away from a familiar critique of heritage experiences as inauthentic or overly commercial, I consider three aspects of the experiential that might (re)shape critical engagements with the past in the present. Building on the work of Kidd (2018), the first engages with the growing trend for 'immersive' experiences in museums and heritage sites. The second draws on Perry's notion of archaeological 'enchantment' (2019) as a new 'moral model' for the field. The third applies Bishop's (2012) reading of artistic 'autonomy' to specially designed heritage experiences. These concepts are then explored in relation to Critical Heritage Studies and tested against four micro case studies that engage in different ways with the experience of heritage. The theorisation put forward here serves as a point of departure for the two-year research project New Trajectories in Curatorial Experience Design (Feb 19-Jan 21), which aims to document and analyse emerging trends in experiential design within the heritage sector. In particular, this position paper highlights specific points of intervention where new forms of critical-creative practice might open up heritage interpretation to alternative experiential strategies and outcomes.

\section{Introduction}

In recent years so-called 'immersive experiences' have become a prominent feature of the cultural calendar across the UK (and further afield). At the time of writing (November 2019), one could, if one so desired (and if issues of accessibility and money were not a concern), spend a weekend in London attending 'The Wolf of Wall Street Immersive Experience' (cheapest ticket £59.95), a 'War of the Worlds Immersive Experience' (£42.45), an immersive audio-visual installation

UCL Institute of Archaeology, London WC1H OPY, GB c.sterling@ucl.ac.uk exploring ecological collapse produced by 'experience gurus' United Visual Artists (Bucknell 2019), and a retrospective of the Danish-Icelandic artist Olafur Eliasson at Tate Modern (£18), whose immersive installations offer 'possibly the most Instagram-friendly exhibition ever' (Thompson 2019). Such experiences demonstrate the buoyancy of the UK's 'immersive economy' - a wide-ranging field characterised by the use of virtual, augmented and mixed reality technologies that has been earmarked by the government as a key area of economic growth over the next decade (Mateos-Garcia, Stathoulopoulos and Thomas 2018). 
While certain forms of immersive and experiential design have been a key feature of archaeology and heritage interpretation since at least the 1980s (the Jorvik Viking Centre for example opened in 1984), the rapid expansion of this field as part of the broader 'experience economy' (Pine II and Gilmore 2011) has been identified as a key area of research for the sector moving forwards (Gröppel-Wegener and Kidd 2019; Kidd 2018). Key questions here relate to the aesthetic, empathetic and narrative possibilities opened up by emerging technologies (Loh 2017), the different modalities of participation and engagement promoted in and through immersive experiences (Bishop 2012; Kidd 2018), and the challenges of developing impactful events and activities within a competitive market. This builds on long-standing work in critical heritage studies exploring the meaning, value, production and impact of heritage 'experiences' globally (Harrison 2013; Hetherington 2014; Hewison 1987; Holtorf 2005; 2009). As Bella Dicks argued some time ago, heritage has never been about simply conserving the past, but rather seeks to stage history as a 'visitable experience' (quoted in Harrison 2013: 86).

Building on this work, the current paper asks to what extent newly emerging approaches to experience design might shape critical heritage thinking and practice. The design of heritage experiences encompasses exhibitions and installations, wayfinding and graphics, audio-visual media and carefully scripted tours. Distinct from yet overlapping with digital 'user experience design' (Hassenzahl 2013), the multitudinous forms of experience now embraced by the heritage field cannot be understood merely as a commodifying apparatus of historical erasure. How might a renewed engagement with the design of heritage experiences provoke alternative perspectives on the past in the present, and what can novel forms of immersive and experiential encounter bring to critical heritage research and practice?

To answer this question, I first define 'immersive' design in relation to the broader field of heritage experiences. I then outline a framework for critical heritage research that highlights how alternative approaches to experiential design might contribute to a range of urgent debates across the sector. To develop these ideas further I look to recent definitions of 'enchantment' and 'autonomy' put forward by Sara Perry (2019) and Claire Bishop (2012) respectively. These concepts provide a foundation from which to analyse the critical potential of a number of micro case studies within and beyond the heritage sector. I conclude with a call to embrace the experimental possibilities of heritage as a thing to be experienced, distinct from yet always embedded in the everyday concerns of contemporary life.

The exploratory thoughts put forward here aim to reconceptualise a diverse range of heritage experiences within the framework of the New Trajectories in Curatorial Experience Design (NTiCED) project - a two-year research programme (2019-2021) focused on emerging approaches to immersive and experiential design across the heritage sector. This project responds to and challenges the 'immersive turn' in heritage practice (Kidd 2018), asking to what extent this shift in cultural consumption might also facilitate new models of heritage making. The paper should be read with this broader outlook in mind, which can only be hinted at in the space allowed here.

\section{Experience and Immersion}

In her historical overview of museum and gallery design, Charlotte Klonk notes that experience 'is a category that straddles the boundaries of the personal and the public' (2009: 8). With the emergence of the scientific method in the $17^{\text {th }}$ century, great significance was placed on direct, repeatable observation of natural phenomena, emphasising a form of public experience closely related to the Latin experientia, denoting trial and proof of experiment. For Romanticists however this positivist 'search for truth' was less meaningful than the sensual, intuitive, and subjective domain of personal aesthetic 
experience. Current uses of the term may veer between these poles, with experience encompassing direct observation of facts or events, the knowledge and skills acquired through practical learning, an occurrence which leaves a lasting impression, or - as a verb - the process of encountering or going through a specific event or set of circumstances (e.g. 'the students are experiencing difficulties with their coursework').

Against this backdrop, the types of experience I am interested in here may be understood as a sub-category of what John Dewey called 'having an experience' (1934 [2005]: 37). Distinct from yet embedded within broader notions of experience as a continuous condition of life, Dewey famously contended that we have an experience when the material experienced runs its course to fulfilment. Then and then only is it integrated within and demarcated in the general stream of experience from other experiences' (ibid). Such experiences for Dewey are contingent upon and responsive to wider states of existence, but they are nevertheless defined by a sense of wholeness, carrying their own 'individualising quality and self-sufficiency' (ibid). The museum, the gallery and the heritage site are often seen to epitomise this form of experiential encounter, which Carol Duncan has written about in relation to ritual spaces (2005). The experience of visiting a specific place or event in this framework is 'thought to have a purpose, an end. It is seen as transformative; it confers or renews identity or purifies or restores order in the self or to the world through sacrifice, ordeal, or enlightenment' (ibid: 82). Here then experience emerges as 'a complicated nexus of the perceptual, the social, the inherent, the learned, the familiar, the untenable, and the possible' (Uchill 2016: 55).

Pine II and Gilmore's definition of the 'Experience Economy' (2011) has shaped many debates in this area over the past two decades. Within this economic model, experiences are primarily understood as a form of value creation, where customers pay for the time they spend in places or undertaking certain activities. This is a familiar model for museums and heritage sites, which tend to be funded through a mixture of government or philanthropic subsidy and visitor entrance fees. This overlap is not simply operational, however. In defining what makes a particularly engaging experience, Pine II and Gilmore identify a number of factors that will be familiar to heritage practitioners, including entertainment, education, escapism, and the aesthetic. The 'richest experiences' they suggest will encompass all four of these realms, enhancing the aesthetic value of the experience, providing an opportunity to escape from one sense of reality to another, engaging learners in the exploration of knowledge and skills, and offering an enjoyable diversion from everyday life. Their conclusion is also worth noting here, as they argue that the 'sweet spot' for any experience is to create a 'mnemonic place, a tool aiding in the creating of memories, distinct from the normally uneventful world of goods and services' (2011: 60).

Writing on the 'heritage boom' of the 1970s and 1980s, Rodney Harrison has argued that it is impossible to underestimate the impact a focus on 'experiences' has had on various forms of heritage making over the last three decades, from exhibitions and archaeological sites to the performance of intangible heritage traditions (2013: 85). Labelled as inauthentic and overly commodifying by various scholars in the 1980s and 1990s (Hewison 1987; Lowenthal 1985; Wright 1985), such experiences have more recently been re-evaluated for the contribution they might make to the 'dream society' (Jensen 1999) - a version of late modernity in which stories of togetherness, care, peace of mind and adventure matter more than products (Holtorf 2006). In this version of the experiential turn, archaeology and heritage are seen to provide 'memorable experiences that appeal to many people ... [telling] stories that relate to wider trends and themes of our society' (ibid: 167). The widespread uptake of immersive experiences across the heritage sector in recent years should be understood against this backdrop. 
Immersion is an emerging area of research that crosses digital design, mixed reality environments, theatre, games design and spatial practice (Alston 2016; Mallgrave 2018; Scholz and Smith 2016; White 2012). Within the domain of heritage, 'immersive experiences' may encompass multimedia exhibitions, virtual and augmented reality technologies, physical installations and themed participatory events. Here I follow Jenny Kidd, who suggests that immersive heritage practice has a number of key defining characteristics: it is story-led, audience and participation centred, multimodal, multisensory and attuned to its environment' (2018). While such experiences may be 'infused with the digital ... digitality should not be understood as a key defining feature' (ibid). Importantly, Kidd locates the 'immersive' turn in heritage and museum interpretation in relation to other developments in the sector. This includes a 'narrative turn' focused on opening up museological experiences to more diverse voices and stories, an 'affective turn' that aims to understand the emotive and transformative potential of museums and heritage, and a 'ludic turn' characterised by play, performativity and 'game mechanics' across a range of activities (ibid). Drawing on wider engagements with 'the immersive' in theatre studies (Dinesh 2016; Machon 2013; Warren 2017), education (Liu et al. 2017), and VR and games design (Bucher 2017), Kidd defines immersive heritage encounters as 'bounded experience[s] at the nexus of a story, the body and the senses' (2018). Usually site-specific and therefore closely related to the narratives, objects and atmosphere of particular spaces, immersive heritage encounters for Kidd have a particularly profound and fertile power within contexts as loaded with representational and historical potency as museums' (ibid).

Two questions immediately present themselves here. First, how are such initiatives different from previous forms of heritage experience? And second, to what extent do they deviate from the always embodied and multisensorial experience of visiting a museum, gallery or archaeological site? While I do not have space to go into any great depth on these questions in this article, it is important to recognise that specially designed immersive experiences always exist on a continuum with previous and ongoing forms of experiential encounter. As Kidd acknowledges,

'most museum visits in some way arouse the senses and the emotions, and all museums and heritage sites attempt to make the most of their environmental resources. Museums are spaces live with promise and possibility, but also risk and (often) discomfort. It is in positive, negative, and more ambivalent ways that (any) heritage can perhaps be defined as immersive.' (2018)

The range of heritage experiences now designed and - crucially - marketed as immersive is however dizzying. Prominent examples here include: The Atelier des Lumieres in Paris, which immerses visitors in various large scale projections of famous artworks; The Museum of London's Beasts of London exhibition, which retells the history of the city from the perspective of its animal inhabitants; Punchdrunk's 2015 project Against Captain's Orders at the National Maritime Museum - a theatrical exhibition aimed at 6-12 year olds that went 'behind the scenes' of the museum; the recently reopened Sutton Hoo experience, which specifically aims to immerse visitors in the story of the sites discovery and excavation. This is an emerging area that needs mapping, analysing and - importantly - conceptualising with reference to the technologies, practices and impacts emerging within and across different forms of 'immersion'.

While the examples given above are oriented towards 'edutainment', I would like to suggest that there is a critical potential to the design of immersive heritage experiences that should be part of any analysis moving forwards. As Kidd argues, many institutions 
are now open to a reflective engagement with their own material-discursive construction and ongoing power dynamics. Immersive practice offers one way of exploring alternative forms of participation and agency, opening up contentious, affective and provocative narratives that might challenge heritage orthodoxies through new modes of visitation (Kidd 2018; see also GröppelWegener and Kidd 2019). Immersive experiences specifically aim to engage audiences with heritage in different ways, encouraging dialogue, interaction and participation over didactic interpretation. While specific contexts of production and consumption need to be considered with each experience, this model can provide a foundation from which to imagine alternative processes and practices of heritage making.

\section{Four Types of Critical Heritage Research}

Before outlining some of the ways in which immersive heritage experiences might be reconceptualised to extend Kidd's analysis, it may be useful to provide a summary of the different approaches and agendas currently circulating around the notion of 'critical heritage studies'. Without going into great depth on the emergence and expansion of this field over the past two decades (see Harrison 2013; Waterton and Watson 2013; Winter 2013), my reading of the critical in critical heritage studies gestures towards four main areas of research and practice. These can be summarised as follows:

1. Building on the foundational work of Stuart Hall (1999) and the broader politics of recognition as defined by amongst others - Charles Taylor (1994), a core line of critique has developed around the narratives and histories on which heritage is built. Here research tends to focus on the marginalisation of certain communities, experiences and voices in the production of heritage as a form of systemic erasure 'inflected by the power and authority of those who have colonised the past, whose versions of history matter' (Hall 1999: 6). Novel heritage experiences may help to surface these hidden or occluded histories in the service of a more diverse and inclusive account of the past in the present.

2. Related to this has been a wide-ranging critique of the institutions, agencies, policies and agendas through which heritage operates. Drawing on structuralist theories of power and discourse, research in this vein has highlighted the constructed, partial, contingent and sometimes repressive function of heritage within broader systems of colonialism, nationalism, globalisation and cultural elitism. Laurajane Smith's definition of 'Authorised Heritage Discourse' (2006) has been influential across this work, which tends to promote 'bottom up' and 'people-centred' approaches to heritage making. While the design of any heritage experience will be enmeshed in such power dynamics, a focus on co-production, participation, engagement and co-creation may help to subvert dominant processes of heritage making.

3. A third area of critical enquiry has focused on the diverse array of 'products' generated in and through the heritage industry - the exhibitions, sites, objects and interpretive schema that mediate engagements with the past in the present. Initially motivated by a sense that heritage was somehow antihistorical and inauthentic (Hewison 1987; Wright 1985), this line of critique has become more sophisticated with reference to the affective, emotive and dialogic nature of all heritage encounters (Smith, Wetherell and Campbell 2018; Sterling 2020; Waterton and Watson 2014). Specially designed experiences offer one way of refining and expanding the repertoire of heritage products and gaining a better understanding of their social and material effects. 
4. Finally, there has been an increased awareness that heritage has an important role to play in navigating and redirecting many of the urgent problems now faced by global society, from social inequality and climate change to rapid urbanisation and sustainability. Tim Winter underlines this point when he calls for a critique of 'the larger issues that bear upon and extend outwards from heritage' (2013: 533). Such 'issues based research' (ibid: 542) situates critical heritage thinking and practice as a vital interlocutor in shaping more just and equitable futures. Here the experiences produced in and through heritage might be seen as 'testing grounds' for radical, systemic change beyond the politics of memory, empathy and identity.

Clearly this list is not exhaustive. Neither can we in reality disentangle such research questions. There is a constant feedback loop between the dominant narratives told about the past in the present, the policies and discourses promoted by heritage institutions, the experiences encountered in museums and other heritage sites, and the possibility for addressing broader social issues through such practices. These lines of critique should also be understood as part of a wider 'unsettling and subversion' (Hall 1999: 8) of the processes through which heritage is put to work in the world. My aim in mapping out these strands of research then is not to document every aspect of critical heritage thinking, but to show how any heritage 'experience' might be seen as a vital nodal point in the broader heritage complex: a site of contestation, consumption, innovation or transformation. The multi-modal and multi-sensorial 'products' I am interested in here - which may touch on 'real world' issues and challenge or reinforce familiar historical narratives - are always generated in and through specific, embedded heritage practices. Given this, how might we begin to think through the critical potential of heritage experiences, which may expand outwards and feed back into each of the above lines of enquiry?

\section{Enchantment and Autonomy}

To help answer this question I would like to draw on the work of two scholars who engage in quite different ways with the production, staging and effects of participatory experiences. In the field of archaeology interpretation, Sara Perry has recently put forward the idea of 'enchantment' to explain the affective and to some extent uncontainable resonance of heritage sites, objects and experiences (2019). In the field of participatory art meanwhile Claire Bishop's theorisation of 'autonomy' provides a framework to imagine heritage experiences as experimental spaces distinct from yet embedded within the wider world (2012). The overlaps and divergences between these two approaches are discussed here to help contextualise the brief case studies put forward in the next section.

For Perry, archaeological and heritage sites always hold the power to enchant, which is to say that they are able to move us and encourage an 'affective response' that might 'motivate us to act back on the world in constructive, ethically minded ways' (2019: 354). Drawing on the work of political theorist Jane Bennett (2001), Perry suggests that enchantment has a 'purposeful nature' that may be drawn out through 'deliberate design' (2019: 355). Such purposeful enchantment would aim to build on the "wondrous affordances of the heritage record' (ibid: 357), creating actionable triggers of affect, such as engaging people in acts of reciprocity, imitation, replication via verbalization, roleplaying, personalization of experience, legitimate decision-making, humour, challenge, thinking through body-related themes, active listening, agonistic debate, and dialogue' (ibid: 358). Here we can begin to see crucial points of overlap with Kidd's definition of immersive experiences, which are similarly geared towards multi-modal and multi-sensorial forms of heritage interpretation. As both 
scholars note, digital forms of experiential design have been important in opening up this field to new approaches and critiques, but only 'as an agent in a more complex process of enchantment' (Perry 2019: 363). Working against the 'lazy empathy' of many heritage experiences, Perry advocates for a mode of affective enchantment that 'reaps an ethic of generosity and considerate action in or on the world' (ibid: 366). This active mode of enchantment aligns with the critical framework described above, encouraging narratives, practices, products and experiences that might demonstrate the embeddedness of heritage in all aspects of worldly affairs.

Two key points need to be drawn out here for the wider reconceptualisation of critical heritage experiences I aim to develop in this article. First, while Perry's model of enchantment can tell us much about the emotional and affective resonance of certain collections, sites, objects and buildings (and the potential for this resonance to promote ethically minded action beyond the immediate context of heritage), the broader applicability of 'enchantment' to spaces, histories and materialities that are not already defined as heritage remains unclear. With the two examples Perry gives to support her argument - a playful exploration of egalitarianism at the site of Çatalhöyük in Turkey, and a facilitated tour of York Minster that sought to encourage dialogue between strangers on contemporary social issues - the 'enchantment' of the heritage record seems self-evident. How might critical, 'agonistic' (Deufel 2017) dialogue emerge in response to less spectacular sites? A brutalist tower block, for example (Roberts 2017), or a field in South Yorkshire (Deller 2002)? As I explore below, such settings are just as open to the 'higherorder' interpretive coding Perry describes (2019: 361), even if their 'enchantment' is less immediately apparent.

The second key dimension of Perry's framework that needs elaborating relates to the moralistic scope of enchantment. Questioning the threats-based discourse of saving the past, for the future, Perry suggests that recognising the enchantment, wonder and 'infinite possibilities' (ibid: 367) of the archaeological record may constitute a new 'moral model' for the discipline. Heritage practitioners argues Perry are 'singularly positioned to access and ignite sparks of enchantment, suggesting that we have a professional responsibility and moral obligation to systematically investigate their dimensions and analyse their consequences' (ibid: 355). Crucially, this 'moral obligation' would extend beyond heritage, with any experience ultimately seeking to encourage 'social bonding and mutual respect, contributing to greater civic welfare' (ibid: 367). As Perry admits, this 'participatory/public value model' is perhaps the greatest challenge to meaningful work in this field (ibid: 361). Here the challenge comes not just from measuring impacts, but also from the implicit and explicit power dynamics shaping any form of heritage engagement. Following the work of Bernadette Lynch, we might suggest that heritage needs to move beyond a welfare model of engagement to develop 'more political and rights-based definitions of participation by citizens, who are the "makers and shapers" of their own experiences' (2017: 14).

The dilemma of participation also forms a central thread in Claire Bishop's influential book Artificial Hells: Participatory Art and the Politics of Spectatorship (2012). Drawing on this work, I would like to suggest that Bishop's understanding of participatory art can tell us much about the critical potential of heritage experiences beyond the experiential and immersive economies.

A first point to note here is that participatory projects have their own 'experiential regime' and formal aesthetics that 'contribute to and reinforce the social and artistic experience being generated' (Bishop 2012: 8). At its most basic, this regime is one of joining in rather simply than viewing or consuming. Bishop is sceptical of such participation for two main reasons. First, the agenda of social inclusion is now so entangled with the logics of neoliberalism that participatory 
practice and individual socio-economic 'betterment' have become nearly indistinguishable. As Bishop notes, social participation in art (and other areas) is viewed positively within a neoliberal framework precisely because "it creates submissive citizens who respect authority and accept the "risk" and responsibility of looking after themselves in the face of diminished public services' (ibid: 14). The second major concern is that participatory art tends to promote compassionate identification with the other as a key outcome rather than raising consciousness of the structural conditions effecting inequality and injustice at all scales. Here Bishop follows Ulrich Beck in noting that the neoliberal idea of 'community' actually erodes social relations by focusing on 'biographic solutions to systemic contradictions' (Beck in Bishop 2012: 14). In the domain of participatory art, this means that 'an ethics of impersonal interaction comes to prevail over a politics of social justice' (ibid: 25).

For Bishop, participatory art is only able to escape this logic by acknowledging and celebrating its autonomy, and experimenting with aesthetic forms and experiences that enlarge our capacity to imagine the world and our relations anew' (ibid: 284). Building on Jacques Rancière's theorisation of art and politics (2004), Bishop sees the autonomy of artistic practice as one of its chief virtues. Art, she argues, "has an element of critical negation and an ability to sustain contradiction that cannot be reconciled with the quantifiable imperative of positivist economics' (2012: 16). Following Rancière, Bishop labels this space of negation and contradiction aisthesis - 'an autonomous regime of experience that is not reducible to logic, reason or morality' (ibid: 18). In this context it becomes essential to view art 'not as part of a seamless continuum with contemporary labour, but as offering a specific space of experience where those norms are suspended and put to pleasure in perverse ways' (ibid: 238).

I would like to suggest that heritage, like art, may be considered 'a form of experimental activity overlapping with the world'
(Bishop 2012: 284). The autonomous heritage experience in this conception is both made and performed; separate from direct continuous experience yet shaped by the preconceptions and expectations found in this wider domain. The specific autonomy of such experiences - which may occur in contexts and environments far removed from the traditional heritage site - will always be contingent and irregular, but the very status of the experience as autonomous means that a range of critical-creative experimentation is both permitted and desired. Criticality here has less to do with the moral programme of any specific heritage organisation or professional practice than with the capacity to communicate to participants and audiences alike 'the paradoxes that are repressed in everyday discourse, and to elicit perverse, disturbing and pleasurable experiences' (ibid). Let me give a few examples of how this might work in practice.

\section{Critical Heritage Experiences}

On 17 June 2001, around 800 people gathered near the former Orgreave coking plant in South Yorkshire to re-enact one of the most contested events in recent British history. The Battle of Orgreave, as this gathering came to be known, recreated a violent confrontation between police and striking miners which had occurred on the same site 17 years earlier. Planned and orchestrated by artist Jeremey Deller as part of an Artangel commission, the re-enactment brought together former miners, a few former policemen, and members of battle re-enactment societies from across the country. The inclusion of this latter group was central to Deller's vision, as he specifically wanted the re-enactment to become "part of the lineage of decisive battles in English History' (2002: 7).

Crossing a line between social history and performance art, The Battle of Orgreave sought to bring heritage enthusiasts interested in 'living history' together with 'veterans' of a recent confrontation (ibid). In this sense, the re-enactment would sustain awareness of this highly politicised event 
by 're-living it as experience' (Bishop 2012: 35). In her analysis of Deller's project, Jane Rendell admits to a certain degree of scepticism at the idea of empathising with or speaking on behalf of the other through such living history, and the concomitant 'ease with which authenticity is ascribed to experiential accounts of the past' (2006: 61). At the same time, Rendell highlights Deller's work as an example of 'critical spatial practice' for the way it 'reconfigures' a particular place in this case Orgreave - as a critical space in the present (2006: 62). Bishop goes further, suggesting that Deller's project 'summons the experiential potency of collective presence and political demonstrations to correct a historical memory' (ibid: 37). The artist in this context is a 'directorial instigator' (ibid), working in collaboration to produce an autonomous event that would otherwise not exist, since it conception is too idiosyncratic and controversial ever to be initiated by socially responsible institutions' (ibid). As Bishop concludes, 'without engaging the "aesthetic thing", the work of art in all its singularity, everything remains contained and in its place - subordinated to a stark statistical affirmation of use-values, direct effects and a preoccupation with moral exemplarity' (ibid: 38). Deller's curatorial gesture in this instance cannot be reduced to a rhetoric of participation or justice, but must instead be seen as inherently contradictory, drawing together themes of memory, violence, trauma, oppression and 'living history' in a strange concatenation of conceptual art and heritage experience.

This approach is also found in the work of artist-architect David Roberts, who from 2013 to 2014 hosted a number of participatory workshops at Balfron Tower in East London as part of a wider research project on the proposed 'regeneration' of this brutalist icon (Roberts 2017). These workshops included performative encounters in a two bed flat with actors playing Ernö and Ursula Goldfinger - the architect of Balfron Tower and his wife - who famously lived in the building shortly after it was opened in 1968.
As Roberts recounts, the 'Goldfingers' mingled with current residents throughout the workshop, asking about their everyday experiences of the tower 'in a dialogue between past and present' (ibid: 135). The rooms in which this experience took place were dressed with facsimiles of archival material documenting the history of the building, effectively reframing the 'official' heritage record in-situ. This re-staging of the archive and of Goldfinger's personal experience of the building sought to touch on 'the spirit of the original endeavour' of Balfron, which was built on egalitarian principles of social housing for all. Through the immersive workshops

a community was not just re-enacted but, if only temporarily, reconstituted. There was a considerable level of engagement with the material on display. Dressing a flat that is identical to residents' homes as an archive makes it estranging and uncanny, and it forced people to see their own flats differently and acted as a trigger for memories. Alongside the informal theatricality, it created a setting where people stepped outside their daily routine into a mode of critical reflection, to re-examine their estate, their flats and themselves.' (ibid: 140)

In the shadow of the tower's heritage-led regeneration - a process that has now seen many residents forced out of homes they had lived in for decades - the performative and immersive experience designed by Roberts and his collaborators re-enacted the lost future of Balfron Tower as a home: a space designed to benefit some of the poorest members of society, but now subject to the whims of neoliberal housing policies and hollow heritage redemption.

Subverting the material-discursive production of heritage is a key tool in the design of 'critical' heritage experiences. Kidd for example discusses the 2018 multimodal experience I Swear to Tell the Truth at the Imperial War Museum as a critical 
exploration of the museum 'project' more broadly, raising questions about 'conflict, representation, and the circulation of information' through play, interaction, alternative wayfinding and a potentially unreliable audio guide (2018). Created by interactive storytelling and immersive design company ANAGRAM to accompany the exhibition Syria: A Conflict Explored (IWM North, February to May 2018), I Swear to Tell the Truth used the museum as a canvas to observe how stories are told, and to actively - and intimately - think about how we make sense of the world around us' (ANAGRAM 2018). It did this by prompting visitors to reconsider the varied 'truths' of the museum, guided by an assemblage of audio-visual resources (including a 20-page booklet, a 45-minute audio guide and a purpose-built wooden structure). In Kidd's analysis, this form of immersive experience 'provoke[d] participants to consider the kinds of narratives an institution devoted to war and conflict constructs, and to ponder how future museological representations on site might attempt to make sense of our precarious present-day geopolitical situation' (Kidd 2018).

As with all the brief examples discussed here, my final micro case study demonstrates the interlacing of everyday and specially designed experiences in the heritage encounter. In March 2018 the National Trust in partnership with The National Archives created an 'immersive experience' exploring 'what it was like for those campaigning for suffrage in London, before the partial grant of the vote to women in 1918' (NT 2018). Based on the testimony of Lillian Ball, a dressmaker and mother from Tooting who was arrested for smashing a window in 1912, the experience took place in three abandoned spaces in Piccadilly Circus, re-imagined as a Suffragette headquarters, a prison and a tearoom. The participatory nature of the experience included tasks designed to confront 'the difficult decisions' faced by those in the Suffragette movement, including property vandalism and militant action. While this experience offers a useful example of the different ways in which 'hidden histories' and contested narratives might be worked through as part of experimental heritage practice, my own engagement with the story was disrupted by a large-scale protest against violence to women that happened to be moving through Piccadilly Circus at the same time. Here the limits of any 'critical' heritage experience were brought radically to the surface, as the historical injustices of female disempowerment met with the unfolding realities of an all-too unjust present.

The experiential contexts described here expand the notion of enchantment put forward by Perry, which is perhaps most readily associated with spectacular or enigmatic aspects of the heritage record. Importantly, the experiences produced at sites such as Balfron Tower and the basement of a shopping complex in London seek to provoke the kinds of ethical action imagined in this model, even as they challenge familiar definitions of the heritage 'site'. Worth noting here is the fact that such experiences cover a broad spectrum of 'immersion', pushing against the digital-first approach of many current interpretation programmes. Drawing on a 'different set of documentary possibilities that bring affect, imagination and truth into a new experimental configuration' (Demos 2013: 9), these carefully crafted experiences gesture towards the critical potential of heritage as an autonomous regime that is both embedded within and separate from contemporary life.

\section{Conclusion}

This paper has provided an overview of the different ways in which critical heritage research and practice might profitably engage with emerging approaches to experiential design. While many of the early critiques of heritage targeted museum and heritage 'experiences' as inauthentic and overly commodifying (Hewison 1987; Reas and Cosgrove 1993), recent developments in this field demonstrate the critical potential of participatory, immersive, interactive and 
playful approaches to the design of narrative environments (Austin 2018). Rather than reject the logics of the experience economy outright, I suggest that critical heritage thinking might work along the grain of the experiential to uncover the affective, educational, entertaining, escapist and political resonances of these emerging interpretive design practices.

Crucially, this active criticality extends across the four types of critical heritage research I map out above. Experiences such as I Swear to Tell the Truth challenge the production of the narratives and histories on which heritage is founded, providing tools for audiences to disentangle the discursive apparatus of the museum. Initiatives such as David Roberts' Balfron performance open up the institutions and agendas of heritage to diverse voices and experiences, facilitating novel forms of co-design and co-curation. Indeed, the field of experience design as a whole suggests alternative ways of producing heritage beyond the familiar spaces of the museum, the historic house and the archaeological site, resituating heritage as a vital interlocutor in, for example, urban planning and activist movements. Finally, the wide-ranging issues tackled through such experiences, from climate change to the war in Syria, demonstrate how new forms of critical-creative heritage practice might directly address many of the urgent problems facing the world today. Here it is worth noting that projects such as I Swear to Tell the Truth specifically aim to use immersive design to encourage radical systemic change, rather than simply perpetuating empathetic identification across space and time (a familiar ambition of many VR and AR experiences). The interweaving of these critical pathways within heritage experience design represents an important area of research moving forwards.

At the same time, we need to be aware of the problems, challenges and potential negative consequences of the immersive turn'. To this end, Kidd identifies a number of key lines of enquiry for this emerging field
(2018). These include: a critical examination of the different ways in which immersive experiences are curated - i.e. framed, marketed, staged and designed - for different audiences; a more nuanced understanding of the impacts of such programmes, which are often 'ambiguous and hard to measure'; and a close consideration of the resources financial and otherwise - required to create compelling experiences. As Kidd suggests, 'we should be working toward robust methodologies for understanding responses to such experiences "in the wild" beyond simple quantitative metrics' (ibid).

While the secondary research put forward in this paper can only begin to address such issues, the NTiCED project as a whole aims to develop these debates through grounded qualitative enquiry. This will include interviews with those engaged in producing heritage experiences, interdisciplinary workshops with practitioners and audiences, and Participatory Action Research with project partners focused on the design of a new 'experiential' exhibition. This empirical research will test and expand on the models of immersion, enchantment and autonomy outlined here, thus contributing towards a refined conceptual framework for critical heritage experiences.

\section{Funding Information}

The research presented in this paper has been funded by the Arts and Humanities Research Council as part of their Leadership Fellows Scheme (Early Career Route). The wider research project, New Trajectories in Curatorial Experience Design, runs from February 2019 to January 2021. This research responds to a specific highlight notice advertised by the RCUK/UKRI for Innovation Fellowships, with a focus on the Creative and Digital Economy. Grant Reference: $\mathrm{AH} /$ S00436X/1. Project Partners include Barker Langham, MET Studio, and the National Trust.

\section{Competing Interests}

The author has no competing interests to declare. 


\section{References}

Alston, A 2016 Beyond Immersive Theatre: Aesthetics, Politics and Productive Participation. London: Pallgrave Macmillan. DOI: https://doi.org/10.1057/978-1-13748044-6

ANAGRAM 2018 I Swear to Tell the Truth. Available at: http://weareanagram.co.uk/ project/i-swear-to-tell-the-truth/ [last accessed 13 November 2019].

Austin, P 2018 Some distinctive features of narrative environments. Interiority, 1(2): 153-172. DOI: https://doi.org/10.7454/ in.v1i2.20

Bennett, J 2001 The Enchantment of Modern Life: Attachments, Crossings, and Ethics. Princeton, NJ: Princeton University Press. DOI: https://doi. org/10.1515/9781400884537

Bishop, C 2012 Artificial Hells: Participatory Art and the Politics of Spectatorship. London and New York: Verso.

Bucher, J 2017 Storytelling for Virtual Reality: Methods and Principles. New York and Oxon: Routledge. DOI: https://doi. org/10.4324/9781315210308

Bucknell, A 2019 Sonic anthropocene: can sound and video art take on climate change? Elephant 22 October 2019. Available at: https://elephant.art/sonicanthropocene-climate-change-awareness-through-psychedelic-sound-environments/ [last accessed 13 November 2019].

Deller, J 2002 The English Civil War. London: Artangel.

Demos, T J 2013 Return to the Postcolony: Specters of Colonialism in Contemporary Art. Berlin: Sternberg.

Deufel, N 2017 Agonistic interpretation: a new paradigm in response to current developments. Anthropological Journal of European Cultures, 26(2): 90-109. DOI: https://doi.org/10.3167/ ajec.2017.260207

Dewey, J 1934 [2005] Art as Experience. New York: Perigree.

Dinesh, N 2016 Memos from a Theatre Lab: Exploring What Immersive
Theatre 'Does'. New York and Oxon: Routledge. DOI: https://doi. org/10.4324/9781315436050

Duncan, C 2005 The art museum as ritual. In: Corsane, G (ed.) Heritage, Museums and Galleries: An Introductory Reader. London and New York: Routledge. pp. 78-88. DOI: https://doi. org/10.4324/9780203326350_chapter 7

Gröppel-Wegener, A and Kidd, J 2019 Critical Encounters with Immersive Storytelling: Genre, Narrative and Environments. London: Routledge. DOI: https:// doi.org/10.4324/9780429055409

Hall, S 1999 Whose heritage? Un-settling 'the heritage', re-imagining the post-nation. Third Text, 13(49): 3-13. DOI: https://doi. org/10.1080/09528829908576818

Harrison, R 2013 Heritage: Critical Approaches. Milton Park, Abingdon and New York: Routledge. DOI: https://doi. org/10.4324/9780203108857

Hassenzahl, M 2013 User experience and experience design. In: Lowgren, J, Carroll, J M, Hassenzahl, M and Erickson, T (eds.). The Encyclopaedia of Human-Computer Interaction. Available: https://www. interaction-design.org/literature/book/ the-encyclopedia-of-human-computerinteraction-2nd-ed/user-experienceand-experience-design [last accessed 13 November 2019]

Hetherington, K 2014 Museums and the 'death of experience': singularity, interiority and the outside. International Journal of Heritage Studies, 20(1): 72-85. DOI: https://doi.org/10.1080/13527258.201 2.710851

Hewison, R 1987 The Heritage Industry: Britain in a Climate of Decline. London: Methuen.

Holtorf, C 2005 From Stonehenge to Las Vegas: Archaeology as Popular Culture. Altamira Press: Walnut Creek.

Holtorf, C 2006 Experiencing archaeology in the dream society. In: Russell, I (ed.) Images, Representations and Heritage: Moving Beyond Modern Approaches to 
Archaeology. New York: Springer. pp. 161175. DOI: https://doi.org/10.1007/0387-32216-7_7

Holtorf, C 2009 Imagine this: archaeology in the experience society. In: Holtorf, $\mathrm{C}$ and Piccini, A (eds.) Contemporary Archaeologies: Excavating Now. Bern: Peter Lang. pp. 47-64.

Jensen, R 1999 The Dream Society: How The Coming Shift from Information to Imagination Will Transform Your Business. New York: McGraw-Hill.

Kidd, J 2018 "Immersive" heritage encounters. The Museum Review, 3(1). Available at: http://articles.themuseumreview.org/tmr_vol3no1_kidd [last accessed 13 November 2019].

Klonk, C 2009 Spaces of Experience: Art Gallery Interiors from 1800 to 2000. New Haven and London: Yale University Press.

Liu, D, Dede, C, Huang, $\mathbf{R}$ and Richards, J (eds.) 2017 Virtual, Augmented, and Mixed Realities in Education. Singapore:Springer. DOI: https://doi.org/10.1007/978-98110-5490-7

Loh, A K 2017 I Feel You. Artforum. Available at: https://www.artforum.com/ print/201709/alyssa-k-loh-on-virtualreality-and-empathy-71781 [last accessed 13 November 2019].

Lowenthal, D 1985 The Past is a Foreign Country. Cambridge: Cambridge University Press.

Lynch, B 2017 The gate in the wall: beyond happiness-making in museums. In: Oncuil, B. Stefano, M L and Kate Hawke, $\mathrm{S}$ (eds.) Engaging Heritage, Engaging Communities. Woodbridge, Suffolk: The Boydell Press. pp. 11-29.

Machon, J 2013 Immersive Theatres: Intimacy and Immediacy in Contemporary Performance. Hampshire and New York: Palgrave Macmillan.

Mallgrave, H F. 2018 From Object to Experience: The New Culture of Architectural Design. London: Bloomsbury. DOI: https://doi.org/10.5040/9781350059 559
Mateos-Garcia, J, Stathoulopoulos, K and Thomas, N 2018 The Immersive Economy in the UK: The Growth of Virtual, Augmented and Mixed Reality Technologies. Report commissioned by Innovate UK. Available at: www.immerseuk.org/ wp-content/uploads/2018/05/Immersive_Technologies_PDF_lowres.pdf. [last accessed 26 April 2019].

National Trust 2018 Suffragette City. Available at: https://www.nationaltrust.org.uk/ features/suffragette-city- [last accessed 13 November 2019].

Perry, S 2019 The enchantment of the archaeological record. European Journal of Archaeology, 22(3): 354-371. DOI: https://doi.org/10.1017/eaa.2019.24

Pine II, J B and Gilmore, J H 2011 The Experience Economy: Updated Edition. Boston, Mass: Harvard Business Review Press.

Rancière, J 2004 The Politics of Aesthetics: The Distribution of the Sensible. London: Continuum.

Reas, P and Cosgrove, S 1993 Flogging a Dead Horse: Heritage Culture and its Role in Post-Industrial Britain. Manchester: Cornerhouse.

Rendell, J 2006 Art and Architecture: A Place Between. London and New York: I. B. Tauris.

Roberts, D 2017 Make public: performing public housing in Ernö Goldfinger's Balfron Tower. The Journal of Architecture, 22(1): 123-150. DOI: https://doi.org/10. 1080/13602365.2016.1276096

Scholz, J and Smith, A N 2016 Augmented reality: designing immersive experiences that maximize consumer engagement. Business Horizons, 59(2): 149-161. DOI: https://doi.org/10.1016/j. bushor.2015.10.003

Smith, L 2006 Uses of Heritage. London: Routledge. DOI: https://doi. org/10.4324/9780203602263

Smith, L, Wetherell, $\mathbf{M}$ and Campbell, G 2018 Emotion, Affective Practices and the Past in the Present. London: Taylor and Francis. DOI: https://doi. org/10.4324/9781351250962 
Sterling, C 2020 Heritage, Photography, and the Affective Past. London: Routledge. DOI: https://doi.org/10.4324/9780429027185

Taylor, C 1994 Multiculturalism and "The Politics of Recognition": An Essay. Princeton, NJ: Princeton University Press.

Thompson, J 2019 Olafur Eliasson at Tate Modern: 5 must-see artworks from summer's most Instagrammable exhibition. Evening Standard 9 July 2019. Available at: https://www.standard.co.uk/go/london/arts/olafur-eliasson-tate-modernexhibition-things-to-see-a4185926.html [last accessed 13 November 2019].

Uchill, R 2016 Mediating. In: Jones, C A Uchill, R and Mather, D (eds.) Experience: Culture, Cognition and the Common Sense. Cambridge, Mass. and London: MIT Press, 35-55.

Warren, J 2017 Creating Worlds: How to make Immersive Theatre. London: Nick Hern Books.
Waterton, E and Watson, S 2013 Framing theory: towards a critical imagination in heritage studies. International Journal of Heritage Studies, 19(6): 546-561. DOI: https://doi.org/10.1080/13527258.201 3.779295

Waterton, E and Watson, S 2014 The Semiotics of Heritage Tourism. Bristol, Buffalo, Toronto: Channel View Publications.

White, G 2012 On immersive theatre. Theatre Research International, 37(3): 221-235. DOI: https://doi.org/10.1017/ S0307883312000880

Winter, T 2013 Clarifying the critical in critical heritage studies. International Journal of Heritage Studies, 19(6): 532-545. DOI: https://doi.org/10.1080/13527258.201 2.720997

Wright, P 1985 [2009] On Living in an Old Country: The National Past in Contemporary Britain. Oxford: Oxford University Press.

\footnotetext{
How to cite this article: Sterling, C 2019 Designing 'Critical' Heritage Experiences: Immersion, Enchantment and Autonomy. Archaeology International, 22(1), pp. 100-113. DOI: https://doi. org/10.5334/ai-401
}

Submitted: 07 June 2019 Accepted: 14 November 2019 Published: 17 January 2020

Copyright: (c) 2019 The Author(s). This is an open-access article distributed under the terms of the Creative Commons Attribution 4.0 International License (CC-BY 4.0), which permits unrestricted use, distribution, and reproduction in any medium, provided the original author and source are credited. See http://creativecommons.org/licenses/by/4.0/. 